\title{
A Perspectiva de Varejo Sobre a Gestão de Design e do Visual Merchandising
}

Leiliane Maria de Oliveira Abreu

resumo:

Este artigo aborda as relações estabelecidas pelos consumidores em lojas de móveis e artigos de decoração, avaliando o impacto do uso estratégico da gestão de design, visual merchandising e marketing sensorial nos ambientes. Foram analisados os fatores que geram uma convergência entre esses recursos e o impacto disso na escolha e na coexistência do consumo online versus offline, relacionando os fatores que levariam os clientes aos pontos de venda. $O$ método utilizado foi a pesquisa qualitativa com abordagem de investigação descritiva, com aplicação de uma entrevista semiaberta, analisando à experiência dos consumidores sobre a influência do design e visual merchandising que tiveram influência significativa na formação de juízo de valor da marca e decisão de compra.

\section{palavras-chave:}

Gestão de design; Visual merchandising; Varejo; Design 


\section{Introdução}

Empresas de varejo em diversos segmentos estão enfrentando, atualmente, uma disputa constante com os e-commerces, mesmo os segmentos tradicionais, como móveis e decoração que exigiam uma experimentação e visualização dos clientes, a experiência de compra está em constante mudança e atrair o interesse do consumidor é cada vez um desafio maior, diversas empresas já desenvolveram formas de vender mobiliário online, com design diferenciado e possibilidade de customização e até simulações virtuais. O cenário de mudanças cria um conjunto de paradoxos, para os profissionais de marketing, um deles é a interação online versus offline. Ambas devem existir e serem complementares (KOTLER,2017). Sendo assim o grande desafio dessas lojas é chamar mais atenção que as lojas virtuais, mesmo com suas comodidades.

Nesse cenário o design do ponto de venda é um aspecto fundamental para diferenciar a experiência de compra e motivar a visita dos clientes para uma experiência sensorial da compra, os espaços e ambientações exigem cada vez mais significados e formas de provocar o interesse desses clientes, diante dessa demanda o visual merchandising , assim como o marketing sensorial se tornam recursos e estratégias de marketing que podem definir a diferenciação de mercado, assim como o design, "o design é uma ferramenta de gestão que cria diferenciação nas capacidades internas da empresa” (MOZOTA, KLIPSCH, DA COSTA, 2011, p.145).

Segundo BAILEY e BAKER (2014, p.4) a atividade do visual merchandising deve "ser vista como um processo que se estende desde o conceito até a finalização e que tem como propósito criar uma identificação clara da marca, mantendo seus valores". E, reforçam a importância de manter o cliente o máximo de tempo possível dentro do estabelecimento, para que realmente exista consumo. Ainda de acordo com os autores o visual merchandising "é o elo principal que conecta a marca, o consumidor, o produto e o ambiente e deve atrair o cliente para dentro do espaço comercial, envolvêlo e motivá-lo a gastar dinheiro".

Segundo uma pesquisa realizada pelo SEBRAE MG, com a ascensão das classes e do crescimento da construção civil na última década, novos hábitos da população também refletem mercado de varejo de móveis, de feiras do setor espalhadas pelo Brasil, de lojas virtuais e programas de TV que tratam exclusivamente de design doméstico. O consumo de decoração se democratizou, deixando de ser um hábito exclusivo de pessoas de alta renda, mas um desejo comum dos consumidores de diversas classes. Assim como a tecnologia as questões sociais tornaram diferente a maneira como o consumidor encara as marcas, fato que transforma o seu modelo de compra complexo e por vezes subjetivo. A maior loja de produtos Nike no mundo, localizada em Nova Iorque, foi construída com o objetivo de criar uma conexão entre o consumidor e a marca. Os idealizadores do empreendimento disseram que $90 \%$ das vendas da marca são provenientes da loja online e, por isso, essa loja física não foi construída para vender, mas sim promover uma conversa entre o cliente e o vendedor sobre esportes, em um ambiente propício para que, dessa forma, a experiência dentro da loja estimule a compra nos canais digitais, praticando a coexistência dos modelos offline e online.

Esse artigo visa entender o comportamento do consumidor em lojas de móveis e decoração. A questão levantada é como a gestão de design, utilizando-se dos recursos convergentes da gestão de design e visual merchandising, assim como marketing sensorial podem contribuir como ferramenta diferencial que motivasse os consumidores a visitar a lojas físicas de móveis e artigos de decoração. Procurou-se ainda, estabelecer cruzamentos dos conceitos de visual merchandising e gestão de design, identificar características de design de ambiente comerciais em que o visual merchandising é planejado conceitualmente e estrategicamente como diferencial proposto, enumerar as características físicas e sensoriais de maior impacto em lojas de móveis e decoração assim como conhecer a relação e percepção dos consumidores que escolhem se dirigir a uma loja física em detrimento a praticidade da loja online visando a experiência proposta pelo ambiente. 
A gestão de design de um ponto de venda proporciona uma renovação do mesmo e uma maneira eficaz de comunicar a evolução da marca, o visual merchandising como uma ferramenta de marketing estratégica, como procura-se enfatizar aqui também é uma estratégia da gestão de design embora sua relação ainda não seja estudada, mesmo que seus conceitos sejam convergentes em diversas aplicações, diante da limitada disponibilidade de obras acerca dos temas gestão de design, marketing sensorial e visual merchandising, muitas vezes limitado a vitrinismo, sendo assim justificase nessa deficiência uma oportunidade de contribuição desse estudo.

A pesquisa está limitada à consumidores de lojas de móveis e decoração, busca-se um eixo de conversão entre gestão de design, visual merchandising e marketing sensorial visando atingir o objetivo dessa pesquisa. Para entender a percepção dos usuários será necessário um levantamento qualitativo de dados que será realizado na cidade de Belo Horizonte - MG. Assim como levantamento de estudos de casos análogos como referência de aplicação dos conceitos estudados. Levantamento bibliográfico, onde selecionou-se livros e publicações de maneira intencional, com temas relacionados gestão de design, marketing sensorial e visual merchandising, constituirá o referencial teórico desta pesquisa. O método utilizado foi a pesquisa qualitativa com abordagem de investigação descritiva, com aplicação de uma entrevista semiaberta, analisando a percepção dos consumidores sobre a influência do design e visual merchandising que apontaram uma grande influência na formação de juízo de valor da marca e decisão de compra.

\section{Referencial Teórico}

As características dos consumidores atuais apresentam um novo desafio, em meio a um mercado acirrado pela concorrência e do aumento do consumo via internet, a sobrevivência dos pontos de vendas parte da premissa que as marcas consigam se adaptar e criar uma linguagem convergente para os seus múltiplos canais de venda, nesse sentido utiliza-se das lojas físicas do varejo como espaços de imersão e experiência da marca tem sido uma estratégia adotada por algumas marcas. Varejo ou loja de varejo é qualquer empreendimento comercial cujo volume de vendas proceda principalmente de pequenos de lotes de bens ou serviços para consumidores finais (KOTLER, KELLER, 2012) ou em outra definição "é qualquer estabelecimento comercial que exponha serviços ou produtos para venda aos consumidores" BLESSA (2017), algumas inclusive que tinham atuação apenas online ou através de distribuidores como por exemplo, Apple Store, Nike, Natura e Havaianas, que criaram lojas físicas, varejistas, onde o objetivo principal é a experiência do usuário, por meio de interações sensoriais e algumas vezes de uso dos produtos é mais importante do que a venda consumada imediatamente. Diante dessa demanda, conceituou-se gestão de design, visual merchandising e marketing sensorial, com a finalidade de identificar as principais congruências na aplicabilidade dos mesmos e na geração de experiência de consumo.

\subsection{Gestão do design}

BEST (2012) define gestão de design como o gerenciamento bem sucedido de pessoas, projetos e procedimentos que estão por trás da criação dos produtos, serviços, ambientes e experiências que fazem parte da nossa vida diária. Envolve também a gestão das relações entre diferentes disciplinas (como design, gestão, marketing e finanças) e diferentes papéis (clientes, designers, equipes de projetos, stakeholders).

A forma como as pessoas entram em contato com uma organização produz uma impressão na mente do consumidor, ainda de acordo o autor, seja por seu logotipo, loja, escritório ou site, todos são "pontos de contato da marca". Sendo assim, o design está presente no nosso cotidiano de forma tangível em produtos e serviços, para o design toda forma é uma forma de se relacionar e são esses relacionamentos, gerados pelos mais diversos elementos, que influenciam as tomadas de decisões dos designers e gestores acerca de como as pessoas percebem uma organização ou uma marca, ainda segundo o autor o design é definido como um processo de solução de problemas centrado nas pessoas. Essa forma de desenvolver soluções pelo design, atraiu interesse das mais diversas áreas e atualmente 
é um termo recorrente, design thinking, que de maneira simplificada é uma gestão de negócios pensada como um projeto de design.

Design é, antes de tudo, um processo de resolução de problemas. É um modo particular de olhar uma questão e dela projetar uma solução apta e adequada. É uma síntese visual capaz de dar organização àquilo que se mostra aleatório, coordenando conceitos e contextos e exibindo-os a partir de uma coerente estrutura central. Através dele, conhecimentos gerais, sabedorias comuns, fatos e dados deixam de ser desconexos para serem vistos a partir de suas relações possíveis, articulando links e linhas conceituais que são apresentados, ao fim, como diretos, claros e, simplesmente, relacionáveis. GENESINI (2014, p. 14).

Experiência é outro termo tão recorrente quanto design no vocabulário das marcas, um dos maiores desafios atuais de uma marca e de criar momentos de experiências que envolvam produtos e serviços delas na vida das pessoas, isso é fundamental para a manutenção da marca diante da diversidade de produtos e formas de acesso, são as experiências que representam momentos únicos, pessoais, impossíveis de copiar, de imitar e de se repetir em outros meios ou tempos. GENESINI (2014).A user-experience, é a experiência pessoal e intransferível que o consumidor desenvolve com a marca que surge da interação, que cria uma experiência memorável GENESINI (2014). Geralmente o termo user-experience é mais comumente utilizado referente a interfaces digitais, mas interfaces não são exclusividades do mundo digital, o mundo das artes utiliza esse recurso com bastante êxito e foi a arte e não o design, que criou os primeiros grandes espaços capazes de gerar experiências significativas em seus visitantes, e explorar a user-interaction ou design de interação, ). "O design de interação é sobre momentos. E é assim que o compreendemos. Lançamos mão da tecnologia, estratégia, design, colocamos eles em contato e criamos momentos. Momentos de interação porque é com eles que as pessoas se apaixonam." GENESINI (2014), o que significou uma ruptura não só para as artes, mas para os museus como um todo. E hoje temos lojas, restaurantes e livrarias que se destacam por utilizar esses exemplos e conceitos para criar ambientes envolventes, foram os museus e suas instalações conceituais que serviram de inspiração para o surgimento das concept stores.

Concept stores ou lojas conceito, são o esforço ativo e diversificado de construir um ambiente sedutor e envolvente para o consumidor, seguindo o mesmo princípio que acompanha as artes de que transformar um ambiente significa, consequentemente, transformar as relações que se dão no seu interior. GENESINI (2014). As lojas conceito também são uma resposta direta a outro fenômeno: as compras pela internet, com a comodidade de consumir sem sair de casa, os consumidores precisam de um incentivo maior para ir aos pontos de venda, como descobrir coisas e lugares novos, ir a loja agora tem um sentido de lazer e experiência para muito além do consumo KOTLER (2017) e essa é uma oportunidade de comunicação e interação para as marcas na qual o papel da gestão de design é fundamental, pois as lojas conceito são uma consequência da evolução na comunicação, são aplicações de singularidade e de personalidade da marca, uma vez que criam a noção de que aquilo que aquela loja oferece e que o que você consegue dela não pode ser encontrado em nenhum outro lugar. É uma experiência única e exclusiva.

\subsection{Visual Merchandising}

BLESSA (2009) define visual merchandising como “(...) o design, a arquitetura e a decoração para aclimatar, motivar e induzir os consumidores à compra." Ele envolve todos os aspectos do ambiente de varejo, mobiliários, iluminação, sonorização, aroma e claro as diversas formas de exposição do produto são trabalhados em um projeto, toda exibição bem sucedida é projetada como uma história, seguem uma narrativa, uma vez que a propaganda pura ou a simples exposição linear dos produtos que por décadas foi a principal ponte entre as marcas e seus consumidores.

A necessidade de achar o tom certo e identificar o público certo para ser cativante é essencial, após essa definição o papel do visual merchandising é se utilizar das ferramentas que se dispõe para 
desenvolver ambientes que comunique ao público a mensagem que a empresa deseja passar e desenvolver relacionamentos através das experiências de compra. EBSTER, GARUS \& MALHOTRA (2013, p.84) destacaram a característica principal do visual merchandising: "Ele é a "linguagem de uma loja", é como um varejista se comunica com seus consumidores por meio de imagens ou apresentações de produto." Atualmente a internet se adapta perfeitamente ao perfil do consumidor contemporâneo, pouco tempo, dificuldade de mobilidade urbana, dentre outros, fazendo com que a ida a lojas não seja tão prática, o que abre um precedente e uma oportunidade para as lojas ofertarem, através de seus ambientes algum tipo de entretenimento aos consumidores. KOTLER (2017, p.78), utilizando-se do design de ambientes, comunicação visual e interação digital, o visual merchandising é fundamental para que esses ambientes muito mais que gerar compras gerem experiências aos clientes, que ofereça algo mais, que valha o tempo despendido no mesmo.

O ambiente comercial, portanto, vem se destacando como um componente estratégico que permite diferenciar e posicionar as marcas varejistas, além de proporcionar uma experiência que venha reforçar as percepções sobre produtos e serviços. ZORRILLA (2012). Uma das principais atuações do visual merchandising, para atrair os consumidores aos pontos de venda ainda são as vitrines, que são cada vez mais sofisticadas e elaboradas, para atrair os consumidores, o visual merchandising cada vez mais tenta aproximar esses cenários dos consumidores, tentando recriar cenas da vida real, como por exemplo manequins e objetos inseridos no cotidiano dos usuários pretendendo que isso crie uma relação entre as peças expostas e os consumidores ARAÚJO (2018).

Em lojas de móveis, eletrodomésticos, os profissionais têm exposto produtos criando cenários e permitindo que os consumidores, toquem, testem, utilizem os mesmos, sem compromisso de compra para o assim eles possam desenvolver uma familiaridade com os produtos e despertar o desejo de posse. Essa intenção é instigar a curiosidade e criar um ambiente altamente interativo em que o visitante é apresentado a um espaço cheio de opções e estímulos. GENESINI (2014). Talvez um dos exemplos mais emblemáticos no varejo de móveis seja a marca Sueca IKEA, as lojas são praticamente iguais no mundo todo, a arquitetura não é tão expressiva, mas a empresa se destaca em construir cenários que permitem uma experiência da marca e experiência de compras única. No showroom os móveis não são exibidos como peças individuais, mas sim compondo ambientes decorativos, geralmente a grande dimensão da loja, permite que estes ambientes sejam um longo percurso expositivo, onde o consumidor pode experimentar quartos, salas, cozinhas dos mais diversos estilos, mostrando um cenário após o outro, extremamente funcionais que visam estimular os sentidos e desejos dos clientes. KREMER (2009).

\subsection{Marketing Sensorial}

Marketing ou Branding Sensorial, é novo segmento de branding ou gestão de marcas, com estratégias direcionadas a estímulos sensoriais, que promove experiências memoráveis, pois "experimentamos praticamente toda a nossa compreensão do mundo através dos sentidos, que são nossa ligação com a memória. Tocam nossas emoções, passadas e presentes", fazem uso de aromas, sons e texturas, para evidenciar o apelo dos produtos, estimulando um relacionamento envolvente da marca com o consumidor. LINDSTROM, (2012).

Sentidos e imaginação possuem importância no momento da decisão de compra, pois, sentimentos "como diversão, prazer, medo e raiva, por exemplo" BREZZO; COBRA, (2010, p. 249), bem como a imaginação despertada no consumidor pelo produto ou serviço, ambos desencadeados pelo estímulo sensorial, determinarão a escolha de acordo com a evocação de lembranças e sua simbologia. Os cinco sentidos da percepção são: visão, audição, tato, paladar e olfato. Cada um deles é especializado na captação de uma categoria de estímulos do ambiente, portanto, que captam os sinais de energia emitidos pelo ambiente e são enviados para o cérebro propiciando, assim, as experiências sensoriais. GALLAGHER (1993) Ainda segundo os autores, a interconexão existente entre nossos sentidos, que pode influenciar a nossa percepção e provocar uma sinergia sensorial, parece ser um fator espontâneo e, em alguns casos, pode envolver experiências potencializadoras como consequência, como é o caso dos estímulos que podem gerar experiências sinestésicas. 
Todo sentido, adequadamente estimulado, apresenta a possibilidade de manifestar lembranças positivas acompanhadas por emoções, que contribuem para a construção da fidelização de marcas. Os sentidos sensoriais podem ser considerados fundamentais para as reações e atitudes humanas na expressão e aprovação ou reprovação sobre algo, uma vez que todas as reações passam pelos sentidos e aquilo que é absorvido por tais canais desencadeará processos mentais que vão gerar lembranças, desejos e bem estar, ou seja, através de estímulos sensoriais é possível criar vínculos emocionais de um indivíduo com uma marca. KOTLER E SCHMITT (2002).

\section{Metodologia}

A metodologia utilizada na elaboração desse artigo foi pesquisa qualitativa, NEVES (1996) apresenta a pesquisa qualitativa como sendo algo que não busca enumerar ou medir eventos, sendo de sua natureza obter dados descritivos mediante contato direto entre pesquisador e objeto de estudo, tendo uma abordagem investigação descritiva, que busca estruturar uma sequência de conteúdos teóricos recolhidos de leituras de obras de referência, teses, dissertações, artigos publicados em periódicos científicos, estudos publicados em anais de encontros científicos e resumos de pesquisas e focaliza a realidade de forma complexa DUARTE (2006).

O procedimento reúne estudo bibliográfico diverso que promove uma discussão ampla sobre o assunto, permitindo compreender importantes características da Gestão de design, Visual Merchandising e Marketing Sensorial, seus potenciais e técnicas na geração de experiência de consumo assim como a convergência entre eles.

$\mathrm{Na}$ tentativa de conhecer as percepções, a satisfação, as expectativas e as opiniões dos indivíduos, acerca dos ambientes, foi realizado uma pesquisa qualitativa através de uma entrevista semiaberta definida assim por DUARTE (2006), que também a classifica como uma técnica qualitativa de recolhimento de informações, foi aplicada virtualmente através de um formulário de acordo com VERGARA (1997), "o formulário e um meio-termo entre questionário e entrevista.", foi respondido por 56 usuários não identificados. Finalmente os dados foram organizados, redigidos em forma de análise e cruzados com o levantamento teórico sobre os temas principais Gestão de design e Visual Merchandising, ele foi elaborado a partir da relação de questões principais e atributos teóricos que deveriam ser verificados.

\section{Relação entre gestão de design, visual merchandising.}

Segundo o filósofo Hipócrates, há cerca de dois mil anos, o ambiente em que vivemos afeta o nosso bem estar. Um exemplo físico bem comum segundo GALLAGHER (1993) são as perturbações dos ciclos circadianos, que podem provocar bocejos durante o dia e inquietações durante a noite de acordo com a adequada exposição à luz nos ambientes, sendo assim o papel estratégico do design de ambientes visa adequar o visual merchandising as experiências sensoriais objetivadas para cada ponto de venda em seu plano de marketing.

BEST (2012) afirma que, "o design é processo de resolução de problemas centrado nas pessoas.", mas o design pode ser comumente associado a perspectiva criativa e de beleza, onde produtos e serviços são reconhecidos como sendo de "design" apresentam diferencial econômico, porém o design está relacionado também ao modelo gerencial, a gestão através do design, esse é um ponto de convergência fundamental entre as atividades de gestão de design e visual merchandising. A tarefa de gerenciar marcas sugere uma busca na mente dos consumidores sobre o que eles esperam da empresa, enquanto promotora de sensações através de bens e serviços ofertados. Essas impressões foram questionadas aos entrevistados durante a pesquisa questionando inicialmente se os usuários iriam o ponto de venda apenas com o objetivo de experimentar a proposta do ambiente e seguido pelo questionamento da influência desse ambiente na decisão de compra, 38 entrevistados $(67,9 \%)$ responderam que já escolheram ir a pontos de venda apenas para experimentar o ambiente, conforme 
gráfico 1 , destes 31 entrevistados $(55,4 \%)$ responderam que nessas visitas compraram alguma coisa sem planejamento ou necessidade.

Quanto as lojas físicas, alguma vez você escolheu ir a uma loja , sem motivação de compras, apenas pela experiência proposta pelo local? Ex.: Lojas Conceito

56 respostas

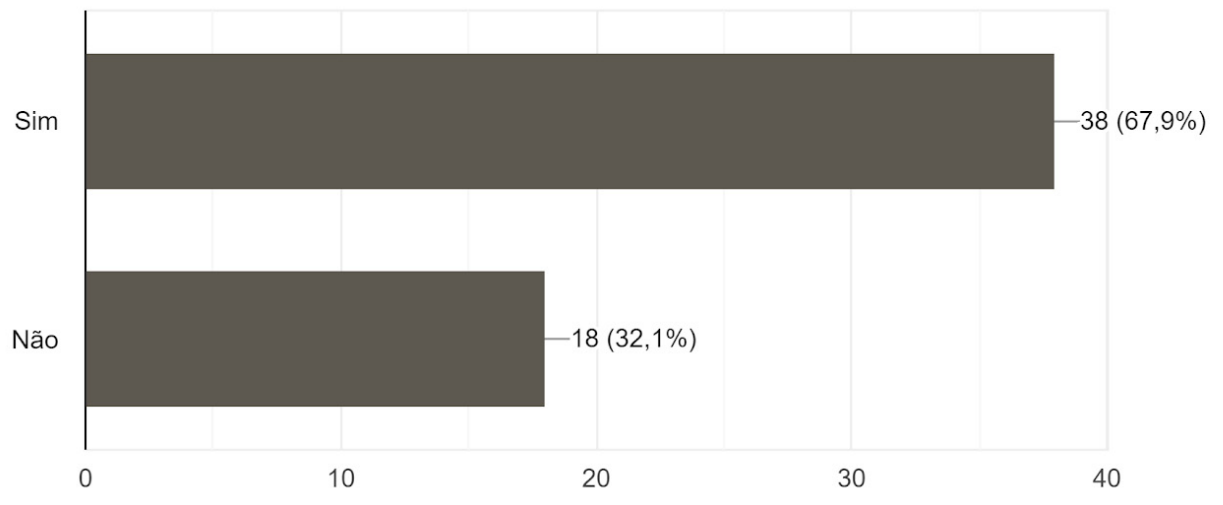

Gráfico 1 - Motivação de ida à loja física.

Segundo KOTLER (2017), ao longo do caminho do consumidor as marcas devem intensificar a criatividade e melhorar a interação dos clientes e as que vão além fornecem aos clientes uma experiência fascinante para além dos produtos e serviços.

Um dos objetivos levantados nessa pesquisa era a interação online e offline nos pontos de venda de móveis e decoração sobre a percepção dos visitantes que se dirigem a loja, dentre muitos desafios, um deles é a interação online versus offline. Ambas devem existir e serem complementares KOTLER, (2017). Conforme sinalizado na metodologia, foi avaliado a apreciação das relações existentes entre gestão do design e visual merchandising em lojas de móveis a partir da análise de conteúdo obtido nas entrevistas, os dados foram divididos em duas categorias, percepção do ambiente e decisão de compras. De acordo com os dados levantados a afirmação confirmou-se, dos entrevistados a maioria afirmou que compraria tanto online quanto offline, conforme gráfico 2.
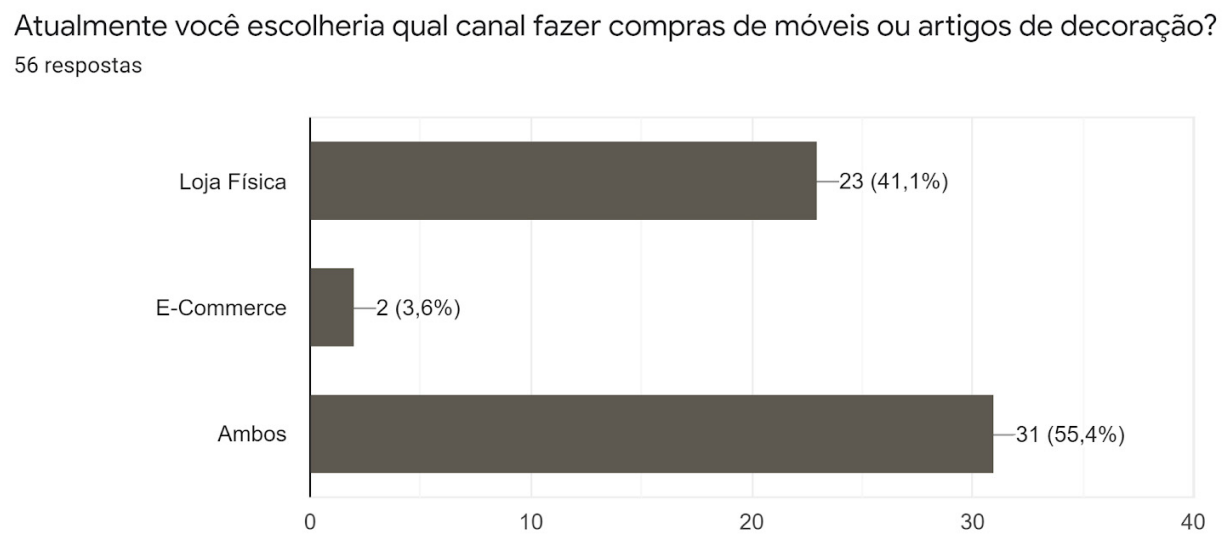

Gráfico 2 - Interação online x offline.

Quanto percepção dos ambientes e do visual merchandising foram questionados sobre os elementos principais que caracterizam uma, para cada entrevistado, uma experiência positiva no ponto de venda. Dentre as características físicas e sensoriais do ambiente, cheiro e temperatura ambos tiveram o maior destaque, das características do visual merchandising, cenário e possibilidade de 
experimentar os ambientes foram os mais citados, tendo quase a mesma relevância que o fator mais importante da experiência no ambiente que foi o atendimento, conforme gráfico 3 , isso demonstra $o$ reconhecimento de um conjunto de ações estratégicas nos pontos de venda e GURGEL (2007) complementa ao dizer que o público consumidor considera, antes de qualquer coisa, o atendimento, a imagem relacionada ao produto, a qualidade, a inovação, a ética da empresa, a garantia oferecida e o acesso a informações referentes aos produtos e serviços oferecidos, esses requisitos contribuem para uma boa experiência de varejo mapeada pela gestão de design e o aplicada pelo visual merchandising.
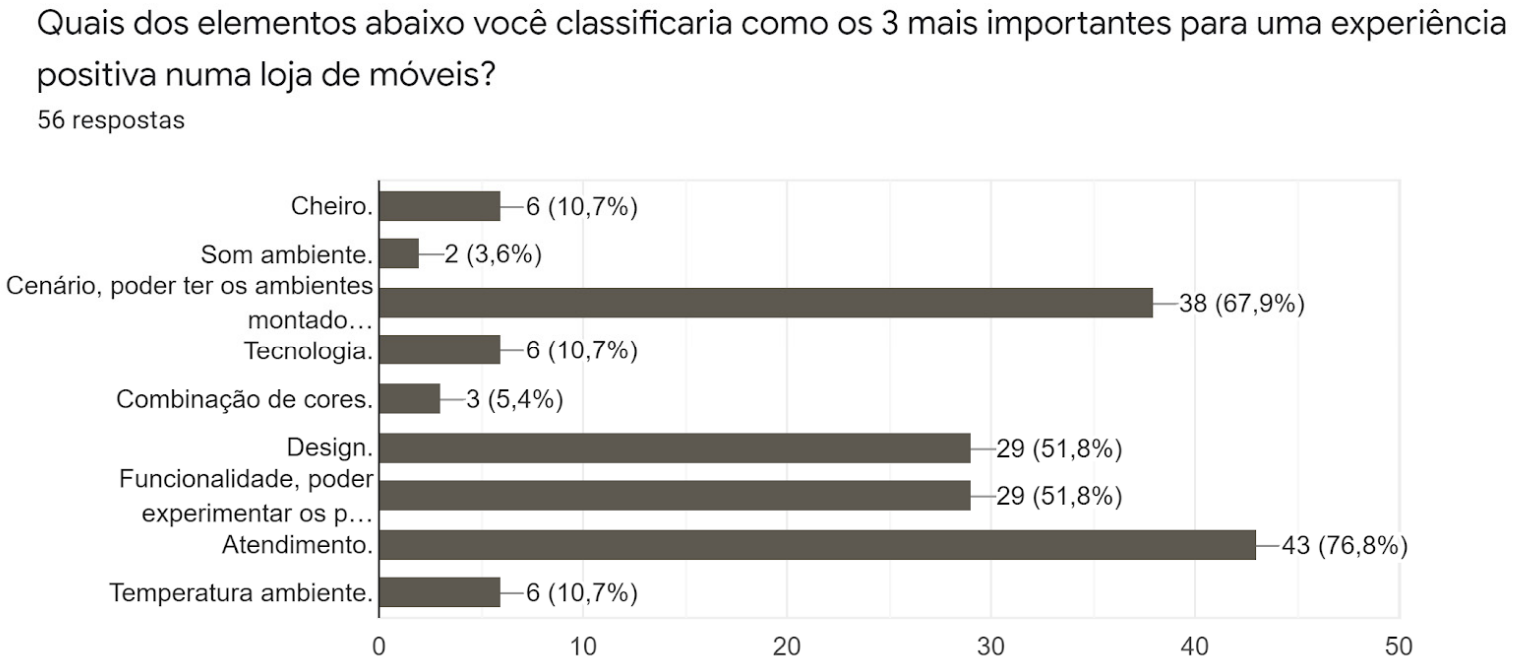

Gráfico 3 - Percepção de ambiente.

\section{Considerações finais}

Os conceitos de gestão de design apontadas nesse estudo permitem uma convergência direta com os de visual merchandising e marketing sensorial uma vez que seu objetivo comum é a experiência da marca no ponto de venda. Através desse contato direto offline, a marca tem a oportunidade de provocar nesse indivíduo uma experiência memorável de compra, através da estimulação dos seus sentidos, resultando numa memória da marca.

Esse estudo possibilitou uma compreensão inicial, pontual e objetiva dos principais pontos propostos. Observou-se que tanto a gestão de design quanto o visual merchandising, atuam no nível estratégico e de planejamento empresarial e está relacionado diretamente com o comportamento de compra, imagem da marca e emoção que envolve desde a criação até a distribuição dos produtos no ponto de venda.

Pela importância e subjetividade do valor percebido pelos clientes nos ambientes, eventuais estudos futuros poderiam buscar entender melhor como o consumidor elabora mentalmente esse juízo de valor. Esse artigo pretendeu-se contribuir para o portfólio de estudos do campo da gestão de design que o associe diretamente ao visual merchandising, um campo prolífico onde cabem diversos estudos, uma vez que essa convergência é pouco comum e o visual merchandising quase sempre é associado a vitrinismo ou a área de moda. 
The Retail Perspective on Design Management and Visual Merchandising

Abstract: This article addresses the relationships established by consumers in furniture stores and decorative items, evaluating the result of the strategic use of design management, visual merchandising and sensory marketing in environments. The factors that generate a convergence between these resources and the impact of this on the choice and coexistence of online versus offline consumption were analyzed, analyzing the factors that would lead customers to points of sale. The method used was qualitative research with a descriptive investigation approach, with the application of a semi-open interview, questioning the experience of consumers about the influence of design and visual merchandising that had a significant influence on the formation of brand value judgment and decision of purchase.

Keywords: Design management; Visual merchandising ; Retail; Design

\section{Referências Bibliográficas:}

ARAÚJO, Walter. Visual Merchandising. São Paulo: Independente, 2018

BAILEY, Sarah; BAKER, Jonathan. Moda e Visual Merchandising. São Paulo: Gustavo Gili, 2014.

BEST, Kathryn. Fundamentos de Gestão de Design. Porto Alegre: Bookman, 2012.

BLESSA, Regina. Merchandising no ponto de venda. São Paulo: Atlas, 2008.

BREZZO, Roberto; COBRA, Marcos. O Novo Marketing. Rio de Janeiro: Elsevier, 2010.

DUARTE, Jorge; BARROS, Antônio. Métodos e Técnica de Pesquisa em Comunicação. São Paulo: Atlas, 2006.

EBSTER,Claus; GARAUS, Marion; MALHOTRA, Naresh. Design de loja e Merchandising Visual:

Criando um ambiente que convida a comprar. São Paulo: Saraiva, 2013.

GALLAGHER, Winifred. Buscando um Lugar para ser feliz. São Paulo: Best Seller,1993.

GENESINI, Letícia. Espaços Interativos: $\mathbf{O}$ design de experiência em marcas e concept

stores. São Paulo: nVersos,2014.

GURGEL, Miriam .Projetando Espaços: Design de Interiores. São Paulo:Senac,2007.

KOTLER, Philip. KARTAJAYA, Hermawan Setiawan, Iwan. Marketing 4.0. 2017. Rio de Janeiro:

Sextante, 2017.

LINDSTROM, Martin. Brandsense: segredos sensoriais por trás das coisas que compramos.

Porto Alegre: Bookman, 2011.

MOZOTA, Brigitte Borja de. Gestão do Design: usando o design para construir valor de marca e inovação corporativa. Porto Alegre: Bookman, 2011.

NEVES, José Luiz. Pesquisa Qualitativa: Características, usos e possibilidades . Cadernos de Pesquisa em Administração. São Paulo: FGV, 1993.

SCHMITT, Bernd H. Marketing Experimental. São Paulo: Nobel, 2002.

VERGARA, Sylvia Constant. Projetos e relatórios de pesquisa em administração. São Paulo: Atlas, 2007.

Visual Merchandising. SEBRAE, 2017. Disponível em: https://cutt.ly/ShVEgRI . Acesso 12/10/2018.

ZORRILLA, P. Nuevas tendencias en merchandising: generar experiencias para conquistar emociones y fidelizar clientes. Madri: Pirámide, 2002. 